\title{
Role of Percutaneous Transluminal Coronary Angioplasty in Acute Myocardial Infarction
}

\author{
BERTRAM PITT, MD, ERIC J. TOPOL, MD, and WILLIAM W. O'NEILL, MD
}

he significant reduction in mortality after administration of intravenous streptokinase noted in a multicenter Italian trial (GISSI) ${ }^{1}$ in more than 11,000 patients in conjunction with similar trends from pooled, randomized studies in more than 10,000 patients $^{2}$ marked the beginning of the "reperfusion era." Intravenous thrombolytic therapy when administered within the first 4 to 6 hours of acute myocardial infarction (AMI) appears effective and is likely to become standard practice, whether with streptokinase, urokinase, tissue plasminogen activator or other thrombolytic agents under investigation. Intracoronary streptokinase therapy, although effective in causing thrombolysis in up to $80 \%$ of patients, compared with the 30 to $60 \%$ rate found with intravenous streptokinase, has not been convincingly shown to significantly reduce mortality. ${ }^{2}$ The apparent failure of intracoronary streptokinase to significantly reduce mortality and improve ventricular function may in part be due to the delay in time of administration necessitated by angiography and in part by the limited number of patients studied to reach statistical significance. Regardless, the proved efficacy of intravenous thrombolytic therapy reduces the need for intracoronary thrombolysis in view of the effort and cost associated with intracoronary administration.

Although intravenous tissued plasminogen activator appears to be more effective than intravenous streptokinase in causing thrombolysis ${ }^{3,4}$ and can achieve successful reperfusion in 70 to $80 \%$ of patients if administered within the first few hours of onset of symptoms, it has a limitation in common with streptokinase in that at best it can only lyse the thrombus but cannot relieve the underlying residual stenosis. The underlying residual stenosis predisposes to recurrent

From the Division of Cardiology, Department of Internal Medicine, University of Michigan Medical Center, Ann Arbor, Michigan. Manuscript received January 14, 1987; revised manuscript received and accepted March 2, 1987.

Address for reprints: Bertram Pitt, MD, Division of Cardiology, University Hospital, 1500 East Medical Center Drive, 3910 Taubman, Ann Arbor, Michigan 48109-0366. thrombosis, resulting in a relatively high incidence of reocclusion and subsequent ischemic events. ${ }^{5}$ In fact, intravenous thrombolytic therapy does not appear to completely lyse the thrombus, as evidenced by recent angiographic studies. ${ }^{6}$

A recent random study comparing the effects of intracoronary streptokinase to percutaneous transluminal coronary angioplasty (PTCA) suggests that PTCA will have an important role in the therapy of AMI. ${ }^{7}$ Although both intracoronary streptokinase and PTCA resulted in an almost identical reperfusion rate of approximately $85 \%$, PTCA was more effective in improving global and regional ventricular function, reducing the frequency of postinfarction angina, exercise-induced ischemia before hospital discharge, and reocclusion. The improvement in global left ventricular ejection fraction with PTCA in patients during AMI, first noted by Hartzler et $\mathrm{al}^{8}{ }^{8}$ is thus confirmed. The significantly greater improvement in global and regional ventricular function with PTCA compared with intracoronary streptokinase therapy despite a similar thrombolytic rate is a result of relief of the underlying residual stenosis. Subsequent studies in patients with AMI also have suggested that the degree of residual stenosis in the infarct-related artery determines the degree of the immediate improvement in coronary blood flow. ${ }^{9}$ The improvement in coronary blood flow resulting from a reduction in the degree of residual stenosis is directly correlated with improvement in global and regional myocardial function before hospital discharge. ${ }^{9}$ There is also a significant relation between time of reperfusion from onset of symptoms and subsequent improvement in ventricular function. ${ }^{9-11}$ Thus, from our own and other studies it would appear that both the time to reperfusion and the degree of residual stenosis in the infarct-related artery appear critical for any reperfusion strategy.

PTCA appears especially promising in patients with severe left ventricular dysfunction or cardiogenic shock. Initial pilot studies in patients with cardiogenic shock suggest that the mortality rate of cardiogenic shock is reduced compared with the previous reported experience with inotropic therapy and intravenous 
thrombolytic therapy. ${ }^{12}$ Although PTCA alone has been shown effective in improving both global and regional ventricular function and recurrent ischemic events, it is unlikely to be the strategy of choice because of the time delay necessitated by the need for angiography and PTCA. Thus, sequential intravenous thrombolytic therapy followed by PTCA has been explored $^{13,14}$ and is undergoing evaluation in several prospective randomized trials.

Although still relatively early, the role of PTCA in the therapy of AMI is beginning to emerge. The results of the Thrombolysis in AMI trial (TAMI) ${ }^{15}$ suggest that in patients in whom reperfusion is successful after intravenous tPA but who have a significant residual stenosis (more than $50 \%$ diameter narrowing), emergent PTCA may not be necessary. The strategy of emergent PTCA for all patients with a significantly narrowed infarct-related artery after successful thrombolysis results in use of the procedure in many patients with critical stenoses within the early hours of reperfusion who on follow-up 7 days later do not have a critical stenosis due to further clot lysis. Furthermore, the benefits from emergent PTCA as indicated by an improvement in ventricular function, decrease in the rate of reocclusion and ischemic events do not appear to be significantly different from those in the group in whom PTCA is performed electively or as needed on the basis of a spontaneous recurrence of symptoms or the occurrence of exercise induced ischemia.

Whether performed emergently or electively, PTCA is likely to be an important component of any reperfusion strategy. Once intravenous thrombolysis is initiated and myocardial salvage achieved, patients may be at increased risk for early recurrent ischemia and or reocclusion. Patients in whom intravenous thrombolysis is successful should optimally be observed in a center with the capability for PTCA and or coronary artery bypass graft surgery, because recurrent ischemia or reocclusion may occur within the ear'ly hours after intravenous thrombolysis. Unless the incidence of recurrent ischemia and reocclusion can be reduced after successful intravenous thrombolysis, we must consider further changes in our health care system, such as the emergency helicopter system developed at the University of Michigan ${ }^{16}$ and the regionalization of health care for patients with AMI. If PTCA is performed in a patient with successful intravenous thrombolysis it should be done with surgical standby. Reclosure or dissection of a recanalized artery may result in recurrent symptoms and hemodynamic compromise, which can be corrected by prompt surgical revascularization. Coronary artery bypass graft surgery for complications of emergent PTCA can be accomplished with relatively low risk. ${ }^{17}$

While PTCA and bypass surgery appear effective in relieving ischemia and preventing reinfarction in patients with recurrent ischemia or reocclusion after successful intravenous thrombolysis, it is not without risk. Its role in the elderly and those with a small, uncomplicated transmural AMI must await the results of ongoing prospective randomized trials. Any significant mortality risk resulting from urgent angiography or PTCA would negate this strategy in low-risk patients in whom the initial in-hospital and 1-year mortality rate is low.

The role of PTCA in the 20 to $30 \%$ of patients who fail initial intravenous thrombolysis remains uncertain. Early studies suggest that emergent PTCA is successful in achieving reperfusion in more than $90 \%$ of these patients and that reperfusion is accompanied by significant improvement in regional and global left ventricular function. ${ }^{18}$ Experience from the recent TAMI trial suggests, however, that the success rate of emergent PTCA in this group may be somewhat less than $90 \%$ and the early reocclusion rate high, about $25 \% .{ }^{19}$ While the potential benefits of emergent PTCA in this group are great, so are the risks. Should further studies suggest a need for emergent PTCA in patients in whom intravenous thrombolysis fails, we must develop more effective noninvasive means of identifying patients in whom thrombolysis fails for triage to centers with the capability of PTCA or coronary artery bypass graft surgery. Alternatively, we must develop more effective intravenous thrombolytic strategies that could open more than $90 \%$ of occluded infarct-related arteries, thereby reducing or eliminating the need for early angiography and emergent PTCA.

Of concern is the added cost of reperfusion if PTCA or coronary artery bypass graft surgery either acutely or electively is found to be essential in a large percentage of patients for optimal reduction in mortality after intravenous thrombolysis. Clearly, for this expenditure to be justified, we will need to have evidence that the cost/benefit ratio for this strategy is favorable. Early studies suggest that intravenous thrombolysis and PTCA may allow selection of patients for early hospital discharge with the potential of a saving in net cost. Although we are optimistic that sequential intravenous thrombolysis followed by PTCA will prove effective in high-risk subsets of patients with acute infarction and those with recurrent ischemia and that the expense will be justified we have the obligation to proceed cautiously and await the results of ongoing randomized trials in more patients before generalizing results of initial studies to all patients with AMI.

\section{References}

1. Gruppos Italiano Per Lo Studio Della Streptochinase Nell'Infarcto Miocardio (GISSI). Effectiveness of intravenous thrombolytic treatment in acute myocardial infarction. Lancet 1986:1:397-401.

2. Yusuf S, Collins R, Peto R, Furberg C, Stampfer MJ, Goldhaber SZ, Hennekens $\mathrm{CH}$. Intravenous and intracoronary fibrinolytic therapy in acute myocardial infarction: overview of results on mortality, reinfarction and sideeffects from 33 randomized controlled trials. Eur Heart J 1985;6:556-585. 3. TIMI Study Group. The Thrombolysis in Myocardial Infarction [TIMI] trial. N Engl I Med 1985;312:932-936.

4. I.S.A.M. Study Group. A prospective trial of intravenous streptokinnse in acute myocardial infarction (I.S.A.M.). N Engl | Med 1986;314:1465-1471. 5. Swan HJC. Thrombolysis in acute myocardial infarction: treatment of the underlying coronary artery disease. Circulation 1982;66:914-916.

6. Brown BG, Gallery CA, Badger RS, Kennedy JW, Mathey D. Bolson EL, Dodge HT. Incomplete lysis of thrombus in the moderate underlying atherosclerotic lesion during intracoronary infusion of streptokinase for acute myocardial infarction: quantitative angiographic observations. Girculation 1986; 73:653-661.

7. O'Neill W, Timmis G, Bourdillon P, Lai $P$, Ganghadarhan V, Walton I, Ramos R, Laufer N, Cordon S, Schork MA, Pitt B. A prospective randomized clinical trial of intracoronary streptokinase versus coronary angioplasty therapy of acute myocardial infarction. N Engl Y Med 1986;314:812-828. 8. Hartzler GO, Rutherford BD, McConahay DR, Percutaneous transluminal 
coronary angioplasty: application for acute myocardial infarction. Am J Cardiol 1984;53:117C-121C.

9. Nicklas JM, Diltz EA, O'Neill WW, Walton JA Jr, Bourdillon PDV, Laufer $N$, Pitt B. Regional myocardial perfusion during medical revascularization in acute myocardial infarction. JACC 1987, in press.

10. Koren G, Weiss A'l, Hasin $Y$, Appelbaum D, Welber S, Rozenman $Y$, Lotan C, Mosseri M, Sapoznikov D, Luria MH, Gotsman MS. Prevention of myocardial damage in acute myocardial ischemia by early treatment with intravenous streptokinase. N Engl I Med 1985;313:1384-1389

11. Mathey DG, Sheehan FH, Schofer J, Dodge HT. Time from onset of symptoms to thrombolytic therapy: a major determinant of myocardial salvage in patients with acute transmural infarction. JACC 1905;6:518-525.

12. Meyer J, Merx W, Dorr R, Erbel R, von Essen R, Lambertz H, Bethge C, Schmitz HJ, Bardos P, Minale C, Messmer BJ, Effert S. Sequential intervention procedures after intracoronary thrombolysis: balloon dilatation, bypass surgery, and medical treatment. Int I Cardiol 1985;7:281-293.

13. Topol EJ, Eha JE, Brin KP, Shapiro EP, Weiss JL, Riegel MB, Gottlieb SO, Brinker JA. Applicability of percutaneous transluminal coronary angioplasty to patients with recombinant tissue plasminogen activator mediated thrombolysis. Cathet Cardiovasc Diagn 1985;11:337-348.

14. O'Neill W, Erbel R, Laufer N, Walton J, Bates E, Topol E, Bourdillon PD, Meyer J, Pitt B. Coronary angioplosty therapy of cardiogenic shock complicating acute myocardial infarction (abstr). Circulation 1985;72:suppl III:
III-309.

15. Topol EJ, Califf RM, George BS, Kereiakes DJ, Abbottsmith CW, Timmis GC, Candela RI, Stack RS, O'Neill WW. A multicenter randomized trial of intravenous recombinant tissue plasminogen activator and emergency coronary angioplasty for acute myocardial infarction: preliminary report from the TAMI study (abstr|. Circulation 1986;74:suppl 11:11-23.

16. Topol EJ, Fung AY, Kline E, Kaplan L, Landis D, Strozeski M, Burney RE, Pitt B, O'Neill WW. Safety of helicopter transport and out-of-hospital intravenous fibrinolytic therapy in patients with evolving myocardial infarction. Cathet Cardiovasc Diagn 1986;13:151-155.

17. Kereiakes D], Topol E], George BS, Abbottsmith CW, Stack RS, O'Neill WW, Candela R]. Califf RM. Emergent coronary bypass following intravenous recombinant tissue plasminogen activator therapy for acute myocardia infarction: results from a multicenter randomized trial (abstr). Circulation 1986; 74:suppl II:II-368.

18. Fung AY, Lai P, Topol EJ, Bates ER, Bourdillon PDV, Walton JA, Mancini J, Kryski T, Pitt B, O'Neill WW. Value of percutaneous transluminal coronary angioplasty after unsuccessful intravenous streptokinase therapy in acute myocardial infarction. Am I Cardiol 1986;58:686-691.

19. Califf RM, Kereiakes DJ, George B], O'Neill WW, Abbottsmith CW, Candela RJ, Stack RS, Topol E]. Failure to reperfuse with tissue plasminogen activator predicts high reocclusion rate after angioplasty (abstr). Circulation 1986;74:supl II:II-25. 